\title{
PURWARUPA APLIKASI PEMBELAJARAN SQL INTERAKTIF BERBASIS WEB DENGAN PENERAPAN GAMIFICATION
}

\author{
Radityo Prasetianto Wibowo, Fachri Hilmi Romdhoni \\ Jurusan Sistem Informasi, Fakultas Teknologi Informasi, Institut Teknologi Sepuluh Nopember \\ Kampus Keputih, Sukolio Surabaya 60111 \\ Telp: (031) 5999944, Fax: (031) 5964965 \\ E-mail: radityo_pw@is.its.ac.id
}

\begin{abstract}
Data is an important element in life. The current information is a combination of existing data. Information from various sources and from various time can form a knowledge. Data in the database can be very powerful if used as possible. How to manage the data of the database is to use the query. For people who do not understand SQL queries, learning SQL query is the mandatory. But the current form of sql learnings media are still in the form of static, less interactive and tedious which is not good for SQLqueries learning process that which also highlight the skills in addition to the understanding. Based on these problems, there is a gap in learning media: static, tedious, costly, and less interactive. Hence the need for a medium of learning about SQL query that can eliminate the existing gap. In this paper we describe about the design of application that implement gamification concept to make interactive webbased applications for the learning of SQL query.
\end{abstract}

\section{Abstrak}

Data merupakan elemen penting dalam kehidupan. Informasi yang ada saat ini merupakan gabungan dari data-data yang ada. Informasi-informasi dari berbagai sumber dan dari berbagai waktu dapat membentuk sebuah pengetahuan. Data dalam database bisa menjadi sangat powerful jika digunakan dengan sebaik mungkin. Cara mengelola data dari database adalah dengan menggunakan query. Bagi orang yang belum mengerti query SQL, belajar query SQL menjadi suatu permasalah sendiri. Media pembelajaran yang berada di internet tidak interaktif sedangkan di lembaga pendidikan formal membutuhkan biaya yang tidak sedikit. Berdasarkan permasalahan tersebut, terlihat gap antar media pembelajaran: terikat waktu dan tempat, membosankan, memerlukan biaya, dan tidak interaktif. Oleh karena itu perlunya sebuah media pembelajaran tentang query SQL yang dapat menghilangkan gap yang ada. Dalam jurnal ini diulas tentang penerapan gamification pada perencanaan dan pembuatan aplikasi interaktif berbasis web untuk belajar query $S Q L$.

Kata Kunci: aplikasi interaktif, gamification, pembelajaran SQL.

\section{PENDAHULUAN}

Perkembangan teknologi informasi saat ini telah mempengaruhi kehidupan masyarakat dalam melakukan kegiatan sehari-hari. Salah satu pengaruhnya yaitu pemanfaatan teknologi informasi di bidang pendidikan. Salah satu pemanfaatan teknologi informasi di bidang pendidikan adalah e-learning. E-learning bertujuan agar seseorang dapat mengasah keahlian dan mendapatkan pengetahuan secara mandiri dengan didampingi instruktur (Popa, 2012). Namun selama ini proses belajar melalui e-learning belum maksimal. Hal tersebut dikarenakan instruktur hanya memberi materi dan tugas yang kemudian dipelajari dan dikerjakan oleh pengguna. Seharusnya penggunaan e-learning dapat membantu penggunanya mempelajari materi secara interaktif, dan membantu instruktur melihat progres keahlian penggunanya. Interaktif disini berarti pengguna dapat menerapkan ilmu yang dipelajari dan mendapatkan feedback secara langsung.

Salah satu contoh penggunaan e-learning yang belum maksimal adalah e-learning untuk mempelajari bahasa SQL (Structured Query Language) yang digunakan untuk mengakses data dalam basis data relasional. Saat ini web elearning untuk mempelajari bahasa SQL yang interaktif masih sedikit, terutama di perguruan tinggi. Masih banyak orang yang merasa kesulitan dalam belajar bahasa SQL secara mandiri. Hal ini terjadi bukan hanya karena web e-learning tidak interaktif, tapi juga karena faktor bosan dan tidak ada motivasi dalam menggunakan e-learning tersebut. Dengan penerapan gamification pada e-learning, pengguna dapat terus termotivasi untuk menggunakan e-learning, menyelesaikan pembelajaran yang ada, dan terus mengasah keahlian SQL-nya. Dengan adanya 
Wibowo, dkk., Purwarupa Aplikasi Pembelajaran SQL Interaktif Berbasis Web dengan Penerapan..

permasalahan tersebut, maka dikembangkan lah sebuah aplikasi berbasis web sebagai media untuk belajar bahasa SQL. Selain interaktif, aplikasi tersebut dirancang dengan konsep gamification. Konsep gamification bertujuan agar pengguna merasa senang dan tidak bosan saat menggunakannya sehingga pengguna bersemangat dan terus menggunakan aplikasi tersebut.

Gamification adalah sebuah proses penggunaan teknik desain game dan mekanisme game pada konteks non-game untuk mengikat pengguna untuk mencapai suatu tujuan (Zichermann, 2011). Sedangkan Nugroho menyatakan bahwa gamification adalah sebuah upaya untuk mengimplementasikan konsep game yang tepat agar mampu menghadirkan proses yang menyenangkan serta benefit yang nyata bagi semua pihak yang terlibat di dalamnya (Nugroho, 2014). Edukasi dapat diberikan melalui mekanisme Instructor-led atau Computer-based. Instructor-led menekankan pada gaya pembelajaran dengan pembimbing dan biasa digunakan dalam pendidikan formal (sekolah, perkuliahan) dan juga non formal (orangtua dengan anak). Kelebihan mekanisme ini adalah pembelajaran menjadi interaktif karena melibatkan interaksi lebih dari seorang. Kekurangannya adalah keefektifannya yang akan berkurang dengan bertambahnya yang diajar. Sedangkan Computer-based adalah gaya pembelajaran yang dilakukan sendiri tanpa adanya pembimbing. Kelebih mekanisme ini adalah murah atau bahkan tidak memerlukan biaya dan setiap orang dapat melakukan kapanpun yang diinginkan.

Gamification dalam edukasi dapat menggabungkan kelebihan dalam dua mekanisme pembelajaran serta menghilangkan kekurangannya. Gamification dapat membuat orang terikat dan termotivasi untuk belajar tanpa harus ada pembimbing seperti pada mekanisme pembelajaran Instructor-led. Gamification dapat membuat proses pembelajaran menjadi interaktif meskipun dilakukan dengan mekanisme Computerbased. Secara umum dalam permainan terdapat empat tipe pemain:

1. Achievers: Harus berada di posisi teratas

2. Explorers: Harus mencari sesuatu yang baru

3. Socializers: Harus berinteraksi dengan pemain lain

4. Killers: Harus mengeliminasi pemain lain

Sedangkan siklus hidup pemain setidaknya ada tiga yaitu:

1. Newbie: Pemain baru, pemain tipe ini butuh panduan. Level awal harus mudah dan membantu pemain agar terbiasa dengan permainan.
2. Regular: Setelah pemain mengetahui permainan, permainan harus menjadi kebiasaan untuk pemain tipe ini. Beberapa level selanjutnya harus menyediakan kepuasan bagi tiap tipe pemain.

3. Enthusiast: Tipe pemain ini telah menjadi master dalam permainan dan butuh twist dan tantangan untuk lanjut bermain.

\section{METODOLOGI}

Metodologi penelitian ini terdiri dari desain interaksi, desain gamification dan implementasi sistem.

\subsection{Desain Interaksi}

Proses interaksi merupakan hubungan yang terjadi antara pengguna dengan pengguna, dan pengguna dengan sistem.

\section{Eksekusi SQL Statement}

Aplikasi Pembelajaran SQL memungkinkan user mengeksekusi SQL Statement yang ditulis pada editor. Aplikasi Pembelajaran SQL memungkinkan user menggunakan database sementara. Ketika SQL Statement akan dieksekusi, database sementara dibuat. Setelah database dibuat, DDL terkait dari Tutorial, Quiz, atau Challenge dieksekusi. Setelah itu barulah SQL Satement user dieksekusi dan kemudian hasil eksekusi ditampilkan.

\section{Pengecekan Jawaban User}

Aplikasi Pembelajaran SQL menyediakan Tutorial, Quiz, dan Challenge yang mana ketiganya tersebut melibatkan jawaban User. Jawaban tersebut dicocokan dengan kunci jawaban yang telah dibuat sebelumnya. Adapun cara untuk mengecek jawaban user adalah membandingkan String. Membandingkan string dilakukan pada tingkat bahasa pemrograman. String jawaban User dibandingkan dengan kunci jawaban yang ada. Jika keduanya sama, maka hasil perbandingan bernilai benar. Dalam membandingkan string terdapat beberapa kekurangan, yaitu perbedaan kapital huruf pada kunci jawaban dan jawaban, serta karakter yang tidak terlihat seperti karakter spasi dan baris baru.

Membandingkan Output Eksekusi dilakukan pada tingkat database. Output eksekusi kunci jawaban dibandingkan dengan output eksekusi jawaban user, jika sama maka bernilai benar. Saat melakukan studi literatur, penulis menemukan statement atau sintaksis SQL Server untuk membandingkan dua query yaitu EXCEPT.

Unit test dilakukan pada tingkat database. Dengan menggunakan unit test, Administrator bebas mengecek jawaban user dengan statement 
apapun. Keluaran dari unit test ada dua: salah atau benar, dan keterangan (jika error atau salah). Untuk memudahkan administrator dalam melakukan unit test, penulis juga menyediakan unit test dengan framework tSQLt. tSQLt adalah framework unit test untuk SQL Server. tSQLt sesuai dengan SQL Server 2005 atau terbaru. Tes yang dilakukan menggunakan framework tSQLt berjalan dalam mode transaction, dapat dikelompokkan dalam schema, keluarannya dapat berupa teks atau XML, dan menyediakan fitur untuk membuat tabel fake, view fake, dan stored procedure spy.

Pada saat tertentu ,tidak dibutuhkan pengecekan terhadap jawaban user karena beberapa kondisi. Kondisi pertama adalah saat perkenalan aplikasi. Pada saat ini, user hanya perlu membaca dan mempelajari materi tanpa harus mengetik pada editor. Kondisi kedua adalah saat materia Tutorial mengenai konsep, dimana konsep tidak perlu mengetikan SQL Statement pada editor.

\subsection{Desain Gamification}

Salah satu penerapan gamification ke dalam aplikasi adalah dengan game mechanic. Game mechanic merupakan unsur game yang akan dimasukan ke dalam aplikasi. Game mechanic bisa terdiri dari berbagai macam alat atau objek. Pada bagian ini akan dijelaskan desain game mechanic yang akan diterapkan pada aplikasi. Pada bagian ini mencakup desain game mechanic yang akan diterapkan pada aplikasi Pembelajaran SQL yaitu point, level user, leaderboard, badge, challenge, dan social engagement loop.

\section{Point}

Point merupakan nilai yang dimiliki oleh user. Point dapat bertambah secara sistematik sepanjang waktu. Point dapat ditujukan oleh user kepada user lain sebagai status user tersebut dalam aplikasi. Semakin banyak point yang dimiliki user mengartikan bahwa ia sudah mengakses banyak fitur. Sistem point yang akan dipakai pada aplikasi ini adalah Experience Point. Experience Point merupakan point yang menunjukan user telah memiliki banyak pengelaman dalam aplikasi sesuai jumlah pointnya. Point ini akan berpengaruh kepada level pengguna sehingga untuk naik level pengguna harus memiliki cukup point. Tabel 1 merupakan tabel kegiatan dalam aplikasi yang bisa menambah point user.

Tabel 1 Kegiatan yang menambah point user

\begin{tabular}{ll}
\hline \multicolumn{1}{c}{ Kegiatan } & \multicolumn{1}{c}{ Point yang diberikan } \\
\hline Mengerjakan & Tergantung point tiap \\
Tutorial & Tutorial \\
Mengerjakan Quiz & Tergantung point tiap \\
& Quiz \\
\hline
\end{tabular}

\begin{tabular}{ll}
\hline \multicolumn{1}{c}{ Kegiatan } & Point yang diberikan \\
\hline $\begin{array}{l}\text { Mengerjakan } \\
\text { Challenge }\end{array}$ & 1 point \\
\hline
\end{tabular}

\section{Level user}

Level user merupakan status sosial user dalam aplikasi. Level user dibuat agar user bangga dengan level yang dimilikinya. Juga agar user terus melakukan kegiatan dalam aplikasi untuk mendapatkan point. Kegiatan untuk mendapatkan point ini dapat menjadi tujuan user dalam menggunakan aplikasi. Selain itu, level user dapat menjadi area kompetisi pada aplikasi dimana sesama user saling berlomba untuk menjadi user dengan level tertinggi.

Tabel 2 Level user pada aplikasi

\begin{tabular}{lrr}
\hline \multicolumn{1}{c}{ Level User } & Min Point & Maks Point \\
\hline Unknown & 0 & 99 \\
Newbie & 100 & 249 \\
Aktivis SQL & 250 & 499 \\
SQL Holic & 500 & 999 \\
SQL Addict & 1000 & 1999 \\
SQL Maniac & 2000 & 3499 \\
SQL Geek & 3500 & 4999 \\
SQL Freak & 5000 & 7499 \\
SQL Legend & 7500 & 9999 \\
SQL Myth & 10000 & 14999 \\
SQL God & 15000 & $\sim$ \\
\hline
\end{tabular}

3. Leaderboard

Leaderboard merupakan papan perbandingan nilai user pada Quiz atau Challenge. Pada Quiz, leaderboard disusun berdasarkan nilai terbesar dan waktu terkecil dalam detik. Sedangkan pada Challenge, leaderboard disusun berdasarakan waktu terkecil dalam detik dan yang bisa menyelesaikan challenge. Leaderboard pada aplikasi Pembelajaran SQL memiliki dua jenis. Yang pertama adalah leaderboard yang hanya menampilkan sepuluh user teratas. Pada leaderboard ini seluruh user bisa melihat daftar sepuluh user yang teratas pada tiap Quiz dan Challenge. Yang kedua adalah leaderboard yang menampilkan peringkat user pada Quiz dan Challenge. Pada leaderboard ini user bisa melihat peringkatnya sendiri walaupun tidak masuk ke dalam sepuluh teratas.

\section{Badge}

Badge merupakan reward yang diberikan kepada user dengan syarat tertentu. Setiap badge memiliki syarat untuk mendapatkannya. Badge pada aplikasi Pembelajaran SQL meliputi seputar Tutorial, Quiz, dan Challenge. Sedangkan Tabel 3 merupakan daftar badge yang bisa didapatkan oleh user dengan cara menyelesaikan Tutorial, Quiz, dan Challenge. 
Wibowo, dkk., Purwarupa Aplikasi Pembelajaran SQL Interaktif Berbasis Web dengan Penerapan..

Tabel 3 Badge pada aplikasi

\begin{tabular}{ll}
\hline \multicolumn{1}{c}{ Badge } & \multicolumn{1}{c}{ Deskripsi } \\
\hline The Achiever & Mengerjakan semua Tutorial \\
The Solver & Mengerjakan semua Quiz \\
Street Explorer & Menyelesaikan 50 Challenge \\
City Explorer & $\begin{array}{l}\text { Menyelesaikan 100 } \\
\text { Challenge }\end{array}$ \\
State Explorer & $\begin{array}{l}\text { Menyelesaikan 200 } \\
\text { Challenge }\end{array}$ \\
Country & Menyelesaikan 500 \\
Explorer & Challenge \\
World Explorer & $\begin{array}{l}\text { Menyelesaikan 1000 } \\
\text { Challenge }\end{array}$ \\
\hline
\end{tabular}

5. Challenge

Challenge atau quest merupakan kegiatan dalam apalikasi yang dapat membuat user merasa tertantang untuk masuk lebih jauh kedalam aplikasi. Pada aplikasi Pembelajaran SQL, tantangan yang disediakan untuk user adalah Challenge. Challenge merupakan pertanyaan yang dibuat oleh user untuk user lainnya. Tingkat kesulitan Challenge bervariasi dari yang sangat mudah sampai yang sangat sulit, tergantung dari kemampuan user dalam membuat pertanyaan Challenge. Challenge dapat berjumlah banyak ketika user sudah mulai terikat dengan aplikasi sehingga pilihan Challenge semakin banyak untuk diselesaikan oleh user lain.

\section{Social Engagement Loop}

Social Engagement Loop merupakan perputaran sosial dalam aplikasi untuk mengikat user. Social engagement loop bertujuan agar user kembali ke aplikasi dan jika beruntung akan membawa user baru. Pada aplikasi Pembelajaran SQL, social engagement loop akan diterapkan dengan menggunakan bantuan media sosial Facebook. Media sosial Facebook digunakan untuk menyebarkan kepada teman user tentang point dan badge yang didapat, tutorial, quiz, dan challenge. Hal tersebut merupakan cara yang efektif untuk memberitahukan aplikasi Pembelajaran SQL ke teman-temannya. Media sosial Facebook juga berguna untuk menarik user lama agar menggunakan aplikasi kembali. Misal ketika user sedang berada di timeline Facebook kemudian ia melihat temannya baru saja membuat status tentang point yang didapatkannya dari aplikasi Pembelajaran SQL, maka user tersebut diharapkan mengakses kembali aplikasi Pembelajaran SQL.

\section{HASIL dan PEMBAHASAN}

Tutorial merupakan fitur aplikasi Pembelajaran SQL yang memungkinkan user mempelajari materi SQL dan langsung mempraktikannya dengan cara menjalankan statement yang ia tulis pada kotak jawaban. Seperti yang terlihat pada Gambar 1, kotak sebelah kiri yang ditandai dengan angka 1 merupakan kotak materi tutorial. Pada kotak materi juga dijelaskan data apa saja yang tersedia pada tutorial tersebut. Kemudian kotak jawaban ditandai dengan angka 2 pada gambar. Kotak jawaban merupakan tempat dimana user menuliskan jawabannya yang berupa statement. Terakhir adalah kotak hasil yang ditandai dengan angka 3 . Kotak tersebut merupakan tempat hasil eksekusi dari statement kotak jawaban.

Semua statement user dieksekusi pada sandbox baik saat menjalankan maupun saat pengecekan jawaban user. Sandbox merupakan database sementara milik user yang diakses dengan login sementara. Sesaat setelah statement dieksekusi, login dan database sementara user dihapus (drop). Jadi apapun yang dilakukan user dengan statementnya hanya akan berpengaruh pada databasenya tanpa mempengaruhi database aplikasi. Persiapan sandbox dilakukan pada class statement. Persiapan sandbox melibatkan dua method utama yaitu prepare_statement dan finish_statement. prepare_statement dipanggil sesaat sebelum eksekusi statement user. Sedangkan finish_statement dipanggil sesaat setelah eksekusi statement user.

Pada persiapan sandbox yang pertama kali dilakukan adalah menyiapkan nama database secara acak. Dalam mendapatkan nama acak, penulis menambahkan method rand_string. Method rand_string menerima satu parameter yaitu panjang string yang diinginkan. Setelah itu barulah membuat database dan login sementara dengan menggunakan nama yang didapatkan dari method rand_string. Semua persiapan ini dilakukan dalam method prepare_statement. Setelah sandbox siap, barula statement user dapat dieksekusi. Eksekusi statement user akan dibahas pada sub bab selanjutnya. Setelah statement user dieksekusi, method finish_statement dipanggil. Fungsi finish_statement bertugas untuk menghapus database dan login sementara yang sebelumnya dibuat. Potongan kode method finish_statement dapat dilihat pada Gambar 2 . 


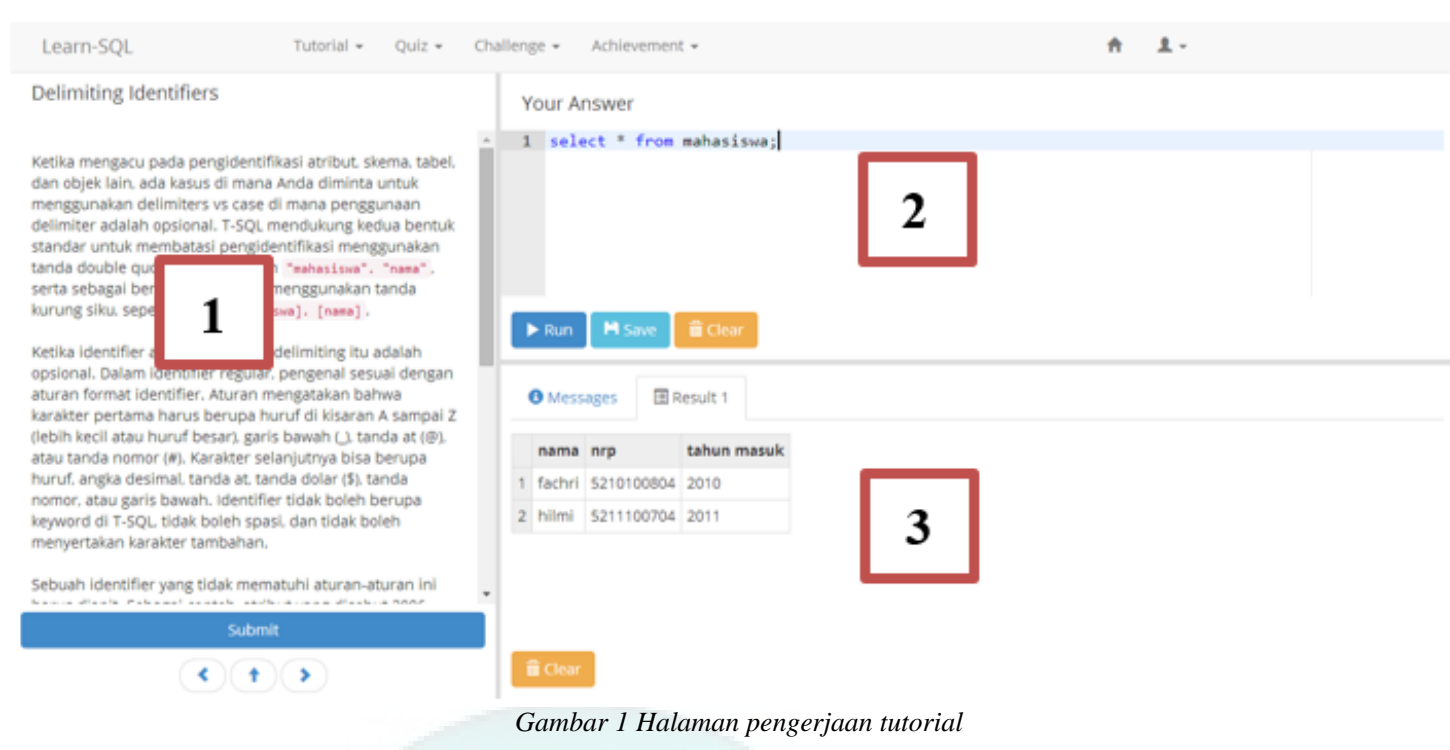

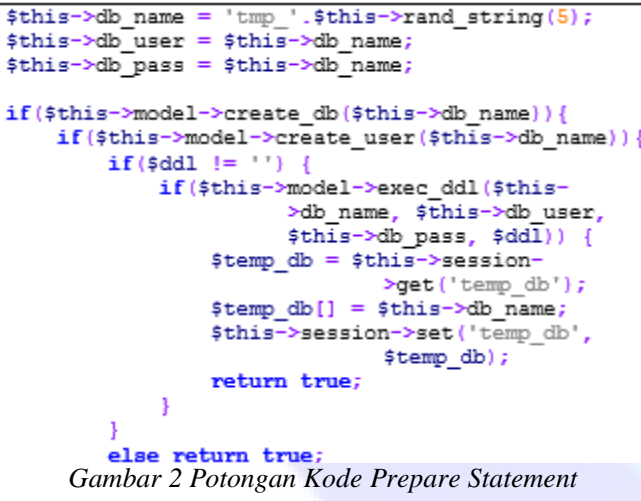

1. Pengecekan Jawaban User

Saat pengecekan jawaban user, method yang dipanggil adalah check_answer. Method ini hanyalah pengatur untuk mengarahkan ke method yang digunakan untuk pengecekan. Method check_answer terhubung dengan method lainnya untuk pengecekan jawaban yaitu compare_string dan check_manual. compare_string merupakan method untuk pengecekan jawaban dengan cara membandingkan string yang dapat dilihat pada Gambar 5.4. Method ini dapat membandingkan string dengan beberapa pilihan. Pilihan pertama adalah case insensitive dimana jika bernilai true maka string dikonversi menjadi huruf kecil terlebih dahulu, jika false maka string langsung dibandingkan. Pilihan yang kedua adalah white space dimana jika bernilai true maka spasi ganda dan karakter baris baru string akan dihapus terlebih dahulu, jika false maka string langsung dibandingkan.

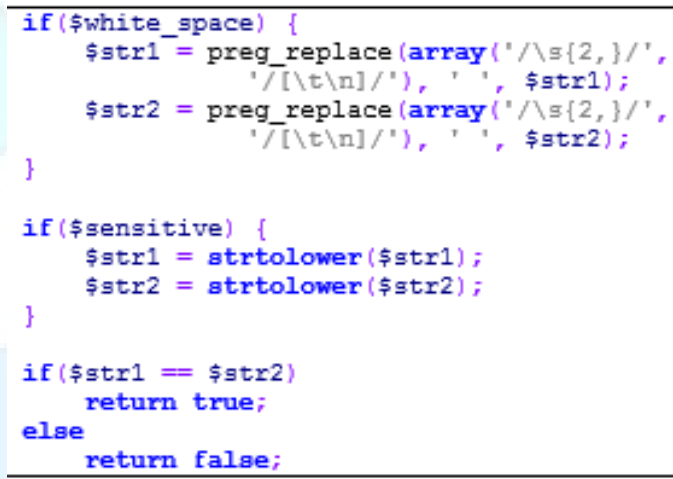

Gambar 4 Potongan Kode method compare_string

Check manual merupakan metode pengecekan yang langkah-langkahnya ditentukan sendiri oleh pembuat tutorial, quiz, atau challenge. Method check_manual merupakan method untuk pengecekan manual. Pada method check_manual, statement user terlebih dahulu dieksekusi, baru setelah itu statement untuk pengecekan dieksekusi. Potongan kode method check_manual dapat dilihat pada Gambar 5.

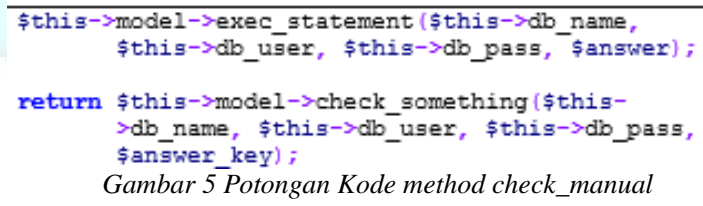

2. Penerapan Konsep Point

Game mechanic ini memungkinkan user untuk menambah point yang dimilikinya. Pada aplikasi Pembelajaran SQL, point dapat diperoleh dari fitur tutorial, quiz, dan challenge. Point berjalan ketika user mengerjakan salah satu dari tiga fitur tersebut. Gambar 6 merupakan contoh ketika user menjawab suatu quiz lalu jawabannya benar dan mendapatkan point. 
Wibowo, dkk., Purwarupa Aplikasi Pembelajaran SQL Interaktif Berbasis Web dengan Penerapan.

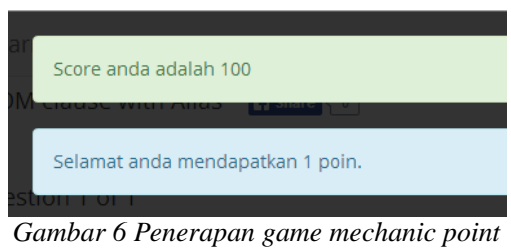

3. Penerapan Konsep Level user

Level user merupakan game mechanic yang bertujuan untuk menunjukan tingkatan user dalam aplikasi. User dapat meningkatkan level dengan cara menambah point. Setiap level user memiliki syarat minimal point. Gambar 7 merupakan contoh ketika user menjawab suatu quiz dengan benar kemudian mendapatkan tambahan point sehingga ia naik ke level Newbie dari level Unknown.

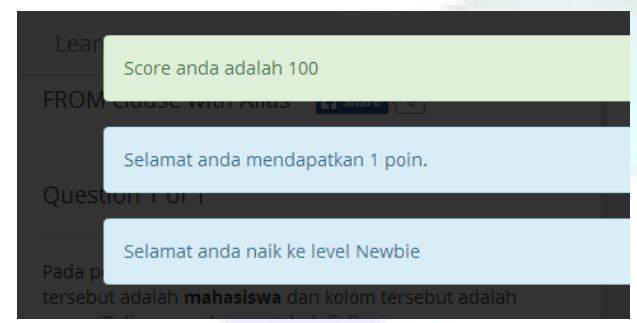

Gambar 7 Penerapan game mechanic level user

\section{Penerapan Konsep Leaderboard}

Leaderboard merupakan game mechanic yang bertujuan untuk mengurutkan dan membandingkan nilai user dengan user lainnya. Leaderboard terbagi menjadi dua: leaderboard yang menampilkan 10 score teratas, dan leaderboard yang menampilkan posisi user. Leaderboard hanya digunakan pada quiz dan challenge. Pada quiz, nilai yang dibandingkan adalah score terbesar dan waktu tercepat. Sedangkan pada challenge, nilai yang dibandingkan hanya waktu tercepat dalam menyelesaikan challenge. Gambar 8 merupakan contoh dari leaderboard yang menampilkan 10 nilai teratas pada suatu challenge.

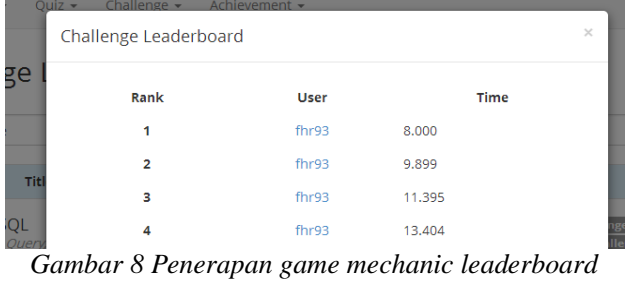

5. Penerapan Konsep Badge

Badge merupakan game mechanic yang bertujuan untuk menghargai kegiatan yang user lakukan di dalam dengan cara memberikan reward berupa badge. Badge juga dapat menjadi simbol bahwa user yang memilikinya telah melakukan suatu usaha untuk mendapatkannya. Gambar 5.9 merupakan contoh ketika user telah menyelesaikan semua quiz yang ada maka user mendapatkan badge The Solver.

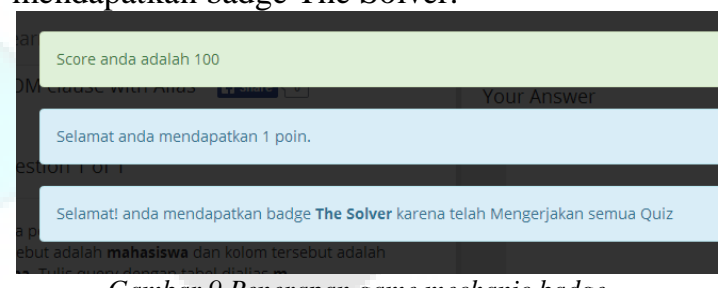

Gambar 9 Penerapan game mechanic badge

\section{Penerapan Konsep Challenge}

Challenge merupakan fitur aplikasi Pembelajaran SQL. Challenge bertujuan untuk memunculkan interaksi antar user secara tidak langsung sehingga user dapat berlama-lama dalam menggunakan aplikasi. Challenge diberi fitur tambahan seperti pencarian, pengurutan, rating, dan lainnya untuk memudahkan user. Hasil penerapan challenge pada aplikasi dapat dilihat pada Gambar 10.

7. Penerapan Konsep Social Engagement Loop Social engagement loop merupakan game mechanic yang membuat user kembali ke aplikasi serta dapat menarik user baru untuk menggunakan aplikasi. Pada aplikasi pembelajaran SQL, penerapan social engagement loop dengan menggunakan media sosial facebook.

\section{Challenge List}

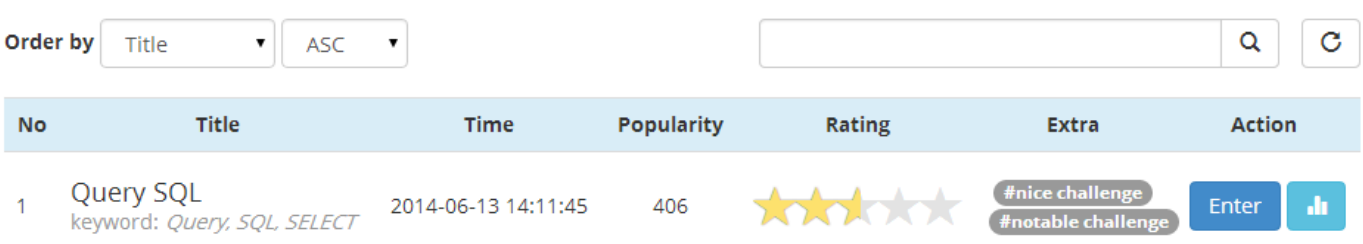




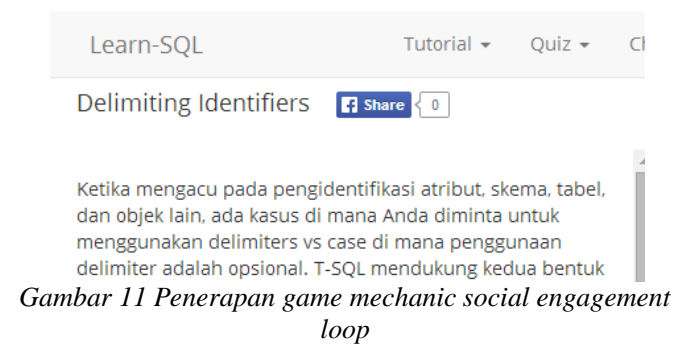

Pada beberapa fitur aplikasi ini diberikan tombol share facebook seperti fitur tutorial, quiz, challenge, dan profil. Fitur yang di-share ke facebook diharapkan akan menarik user baru serta user lama untuk mengakses aplikasi. Hasil penerapan social engagement loop dapat dilihat pada Gambar 11.

\section{KESIMPULAN dan SARAN}

Berdasarkan hasil penelitian, maka dapat disimpulkan sebagai berikut:

1. E-learning untuk belajar bahasa SQL secara interaktif atau yang dinamakan Aplikasi Pembelajaran SQL berhasil dibuat. Aplikasi Pembelajaran SQL memungkinkan pengguna secara interaktif belajar SQL dan mencoba langsung materi yang diajarkan dengan cara menjalankan statement SQL pada aplikasi. Selain itu, pengguna dapat langsung mengetahui nilai dari quiz yang diikuti.

2. Konsep gamification berhasil diterapkan ke dalam Aplikasi Pembelajaran SQL. Penerapan gamification pada aplikasi ini adalah dengan menggunakan beberapa game mechanic yaitu Point, Level user, Leaderboard, Badge, Challenge, dan Social Engagement Loop.

Dalam beberapa use case, didapatkan hasil yang masih belum memuaskan seperti pada proses skenario menjalankan statement infinite loop, sehingga aplikasi tidak memberikan hasil apaapa kepada user dalam waktu dalam waktu yang sangat lama. Walaupun koneksi dengan server sudah terputus, namun statement infinite loop tetap berjalan di SQL Server komputer. Salah satu perbaikan yang dapat dilakukan adalah memberikan timeout pada proses query, atau dengan melakukan filtering terhadap query yang akan dijalankan dengan mendeteksi kemungkinan terjadi statement infinite loop pada query.

Pada uji performa, prototipe sudah diuji dengan metode stress test sampai kondisi konkuren user sebanyak 50 user, dan berjalan dengan baik. Namun, hal tersebut juga dibarengi dengan peningkatan waktu tunggu yang cukup signifikan pada setiap proses yang diujikan. Salah satu aspek yang mungkin memberatkan adalah aspek pembuatan database pada setiap kali pengguna akan menjalankan sebuah query. Berdasarkan hasil investigasi menggunakan tools sql performance dashboard didapatkan 4 Expensive query yang dapat dilihat pada tabel 6.1.

Tabel 4 List Expensive Query

\begin{tabular}{|c|c|c|}
\hline Perintah & $\begin{array}{c}\text { Waktu } \\
\text { Eksekusi }\end{array}$ & Durasi \\
\hline $\begin{array}{l}\text { IF EXISTS(SELECT * FROM } \\
\text { sys.databases WHERE name = } \\
\text { 'tmp_IsjVq' ) }\end{array}$ & 50 & 18.539 \\
\hline $\begin{array}{l}\text { SELECT tutorial.*, topic.title } \\
\text { AS "topic_title" FROM } \\
\text { tutorial LEFT JOIN topic ON } \\
\text { tutorial.id_topic = } \\
\text { topic.id_topic WHERE } \\
\text { id_tutorial = @P1 }\end{array}$ & 24 & 5.219 \\
\hline $\begin{array}{l}\text { IF EXISTS (SELECT } \\
\text { loginname FROM } \\
\text { master.dbo.syslogins WHERE } \\
\text { name = 'tmp bZ94U') }\end{array}$ & 50 & 5.994 \\
\hline $\begin{array}{l}\text { SELECT * FROM challenge } \\
\text { WHERE id_challenge = @ } 1\end{array}$ & 10 & 1.396 \\
\hline
\end{tabular}

Query pertama pada tabel 4 tersebut adalah query untuk mengecek keberadaan database. Query tersebut dijalankan sebelum query untuk membuat database sementara.Query kedua untuk mendapatkan data tutorial. Query ketiga untuk mengecek keberadaan login. Dan yang query terakhir untuk mengambil data challenge. Dari keempat query pada tabel, query pertama menghabiskan waktu 18,539 detik dalam 50 kali eksekusi. Sedangkat total dari empat query adalah 31,148 detik. Berdasarkan keterangan dari dokumen SQL Performance Tool, query yang dicatat hanya DML statement (SELECT, INSERT, UPDATE, DELETE) sedangkan statement lainnya seperti CREATE DATABSE atau DROP DATABASE tidak tercatat yang mana ada kemungkinan dua statement yang tidak tercatat tersebut menghabiskan banyak waktu. Dengan ini dibutuhkan penelusuran lebih lanjut terkait hal ini.

\section{DAFTAR RUJUKAN}

E. M. Popa, "What Is Good e-Learning?", Journal of Knowledge Management, Economics and Information Technology, 2012.

G. Zichermann dan C. Cunningham, Gamification by Design: Implementing Game Mechanics in Web and Mobile Apps, CA: O'Reilly Media, 2011.

E. Nugroho, "Gamification, Bukan Sekadar Bagi-bagi Poin," 10 Juni 2013. [Online]. Available: http://tekno.kompas.com. [Diakses 26 Februari 2014].

"Gamification Education," 26 Februari 2014. [Online]. Available: http://gamification.org/education/ [Diakses 26 Februari 2014]. 
Wibowo, dkk., Purwarupa Aplikasi Pembelajaran SQL Interaktif Berbasis Web dengan Penerapan..

A. Beaulieu, Learning SQL, 2nd Edition, CA: O'Reilly Media, 2009.

I. Ben-Gan, D. Sarka dan R. Talmage, Training Kit (Exam 70-461): Querying Microsoft ${ }^{\circledR}$ SQL Server® 2012, California: O’Reilly Media, 2012.

I. S. Sipahutar, Pengembangan Aplikasi Berbasis Web Interaktif untuk Belajar Dasar Pemrograman Java (Studi Kasus Jurusan
Sistem Informasi ITS), Surabaya: Jurusan Sistem Informasi ITS, 2013.

Microsoft, "EXCEPT and INTERSECT (Transact-SQL)," 4 Juni 2014. [Online]. Available: http://msdn.microsoft.com/enus/library/ms188055(v=sql.110).aspx.

tSQLt, "Welcome to tSQLt - The Database Unit Testing Framework for SQL Server," 4 Juni 2014. [Online]. Available: http://tsqlt.org/. 